\title{
Microrrelatos autoetnográficos. Historias de vida interculturales para la transformación social.
}

\section{Autoethnographic microtales. Intercultural life stories for social transformation.}

\author{
Tiffany López-Ganet \\ Universidad de Granada,
}

\begin{abstract}
Resumen
Con la presente investigación $\mathrm{a} / \mathrm{r} /$ tográfica, pretendo generar una reflexión en torno a la identidad e interculturalidad a partir de un problema que nació en mí: la falta de autoestima por sentirme distinta debido a mi apariencia. A través de una introspección personal, por medio de microrrelatos autoetnográficos, reflexiono acerca de hechos importantes en mi vida que conectan mi autopercepción con conceptos extraídos tales como origen, identidad, migración o transculturalidad, capaces de establecer un discurso teórico más general y colectivo. Los resultados obtenidos serán la base para la posterior aplicación de proyectos culturales y educativos para alumnado, profesorado o investigadores.

Palabras clave: Identidad, Interculturalidad, Investigación Autoetnográfica, Historias de vida, Memoria.
\end{abstract}

\begin{abstract}
With this $\mathrm{a} / \mathrm{r} / \mathrm{tographic}$ research, I intend to generate a reflection around the identity and interculturality from a problem that was born in me: the lack of self-esteem because I feel different due to my appearance. Through personal introspection, through autoethnographic microtales, I reflect on important events in my life that connect my self-perception with extracted concepts such as origin, identity, migration or transculturality, capable of establishing a more general and collective theoretical discourse. The results obtained will be the basis for the subsequent application of cultural and educational projects for students, teachers or researchers.

Keywords: Identity, Interculturality, Autoetnographic Research, Life Stories, Memory.
\end{abstract}

\section{Introducción}

Y, una vez más, ¿quién soy yo?

En palabras de Bauman (2005), preguntar quién eres tú sólo cobra sentido cuando se cree que uno puede ser alguien diferente al que se es.

El punto de partida del presente trabajo es mi propia historia. A través de un acto performativo como es desenredarme el pelo, se produce una introspección personal; sesiones de 40 minutos entre tirones de pelo que me permiten reflexionar una y otra vez sobre quién soy yo. En ellas, surgen los microrrelatos autoetnográficos, narrativas personales entorno a mi realidad que son el eje de la investigación.
Intrínsecos a esa autobiografía, aparecen conceptos como identidad, alteridad, interculturalidad, memoria o migración, que conectan mi autopercepción con un discurso teórico más amplio, común y colectivo, por medio de una metodología basada en las artes.

"Hay algo curioso en la autobiografía. Es un relato efectuado por un narrador en el aquí y ahora sobre un protagonista que lleva su nombre y que existía en el allí y enconces, y la historia continúa en el presente, cuando el protagonista se funde con el narrador" (Bruner, 1991, p.119).

Como investigación autoetnográfica, enfatiza el análisis cultural y la interpretación de los comportamientos de los investigadores (en este caso los míos), de sus pensamientos y experiencias en relación con los otros; la observación y descripción de la conexión entre lo personal y la cultura (Guerrero, 2014).

Siguiendo como metodología la antropología visual, existe algo previo a la creación/aparición/redacción de los microrrelatos autoetnográficos; y es la imagen, esa composición que relaciona la apariencia física del Yo con la de los otros: la razón de que me sintiera diferente, que me pudiera comparar. Mundos visibles y gráficos como procesos sociales, en donde los objetos y las acciones son producidos con la intención de comunicar algo a alguien, lo que otorga una perspectiva ausente en otras teorías (Ruby y Worth, 1981).

Para llegar a materializar esos recuerdos, se ha utilizado la Investigación Basada en las Artes, una forma de investigar acorde con los tiempos posmodernos y en la que se toman estrategias y métodos propios de las artes en su sentido más amplio y diverso (Diamond \& Muller, 1999). Hablamos entonces de utilizar las artes como un método en la investigación; aprovecharnos de su libertad y posibilidades para enriquecer el trabajo.

Tal y como afirma Lyotard (1979) refiriéndose a la posmodernidad, cada uno se ve remitido a sí mismo; "de la descomposición de los grandes relatos (...), se sigue eso que algunos analizan como la disolución del lazo social y el paso de las colectividades sociales al estudio de una masa compuesta de átomos individuales" (Lyotard, 1979, p. 15).

Yo sería uno de esos átomos individuales. Con una perspectiva muy similar a la que se expone en este 
trabajo, Bolívar (2014, p. 716) al citar a Hernández (2011) remarca que la finalidad de la investigación sobre historias de vida es conectar las narrativas personales y biográficas de profesores e investigadores con su contexto sociocultural, histórico e institucional; asegura que esta conexión es la que hace posible que lo individual se convierta en colectivo.

Se pretende así, siguiendo la idea central de la a/r/tography (Springgay, Irwin y Kind, 2005), exponer las tres identidades que forman parte de toda persona comprometida con esta línea de investigación en educación artística, y en este caso, yo: artista, investigadora y docente.

\section{Microrrelatos autoetnográficos}

Cada uno de los relatos personales, en los que la Tiffany del presente narra las vivencias más salientables de la que ya llevaba su nombre años atrás, será el punto de partida para la investigación posterior, estando vinculada a temas como la interculturalidad, la procedencia o la identidad.

\section{Así peinaba, así, así}

Cuarenta minutos. Pierdo cuarenta minutos cada vez que me quiero peinar como el resto de gente con pelo que se peina. Es mucho tiempo, y me da para pensar y pensar. Divido el pelo en cuatro partes, separo los mechones con la mano, los desenredo con el peine de púas para afro, echo productos y productos para suavizarlo y lo trenzo; se seque al aire o con secador, coge su forma esférica. ¿Por qué no se ondea al viento como las demás melenas? Recurro a la memoria para responderme; así una y otra vez.

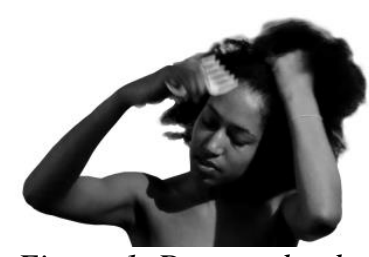

Figura 1. Desenredando

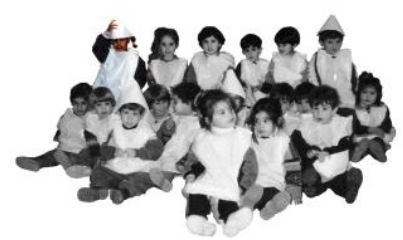

Figura 2. Soy la única marrón.

\section{Soy la única marrón}

Esperaba ansiosa la llegada del primer día de cole. Entré entusiasmada. Volví al día siguiente, y al siguiente. Fui contenta... hasta que vi la foto. Fue la primera vez que me veía en una misma imagen con todo mi grupo de “iguales". Y yo era diferente; la única marrón.

\section{A miña nai é a filla de Baltasar}

Paquita, mi madre, trabajó cuidando a los niños de una familia española que vivía en Malabo (Guinea Ecuatorial) desde que tenía catorce años. Interna. Cada vez que venían a España de vacaciones, ella también con ellos. Y los llevaba al parque aunque ella era una niña más. Mientras columpiaba a la pequeña, se le acercó un niño nervioso: - Sólo quería que le dijeras que fui muy bueno. Quiero que le digas a tu padre que me he portado muy bien este año y que he hecho todo lo que me han pedido. - Oh, ¿de qué conoces a mi padre? - mi madre es muy ilusa, exageradamente. - ¿Tú no eres la hija del Rey Mago Baltasar? O sea, que aquí estoy yo con mi abuelo.

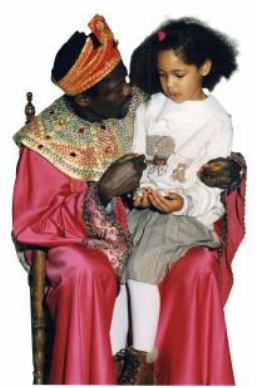

Figura 3. Nieta y abuelo

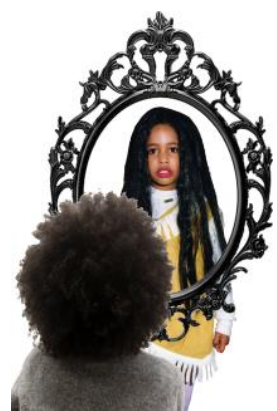

Figura 4. Espejito, espejito

\section{Espejito, espejito mágico}

Desde que fui consciente de los "otros" comenzaron las tan normales comparaciones $\mathrm{y}$, con ellas, mi disgusto.

- Mamá, soy fea. - le decía llorando a mi madre mientras veía mi reflejo en el espejo.

Las lágrimas también discurrían por su cara cada vez que se repetía esta situación por la impotencia que sentía. No me gustaba ser negra, ni tener el pelo rizo. Moría de envidia cada vez que me cruzaba con una melena rubia, lisa y larga. Pasó mi infancia alisándomelo, echándome productos y luchando contra nuestra realidad.

\section{Can de palleiro}

Llegué al mundo gracias a la unión de uno de Visantoña (Galicia, España) con una de Malabo (Isla de Bioko, Guinea Ecuatorial). Soy una cosa, soy la otra, ¿o soy las dos? En el entorno de la familia de mi padre soy la negrita; en el de mi madre, la blanquiña. Mi pareja acabó por denominar mi no-raza "can de palleiro": un pobre ser que nace sin pedigrí.

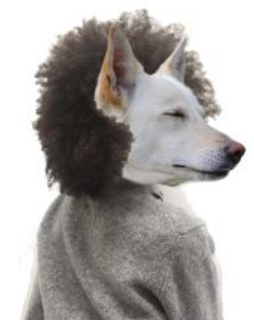

Figura 5. Can de palleiro 


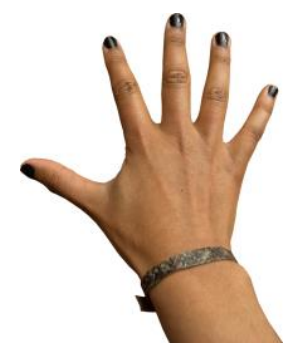

Figura 6. Ebebe

\section{Ebebe}

"Ebebe" es mi nombre en la tribu bubi. Es una serpiente muy especial que habita los bosques de la isla de Bioko (Guinea Ecuatorial). Al ver que tenía un sitio allí, todo cambió. Era una más.

\section{Tribu vs. Parroquia}

Con tres años me uní al grupo de baile y gaitas de mi pueblo. "¡Ai, qué graciosa! Una niña negrita bailando gallego!”. Así una y otra vez. Y mientras yo, venga dengue, venga pololos y trenzas postizas. Decían que bailaba muy bien. Nunca lo vi como nada raro; no tenía otra tradición cerca. Es posible que pegara más en una tribu africana bailando con una falda hecha con hierbas, pero no tuve la oportunidad.; aún no conocía mi nombre Ebebe...

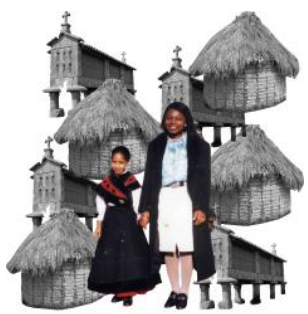

Figura 7. Tribu, parroquia

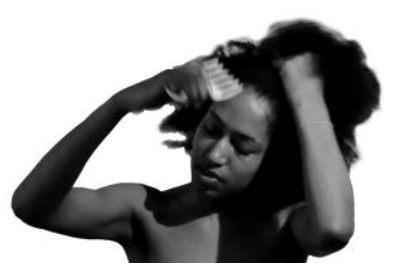

Figura 8. Desenredando

\section{Así peinaré, así, así}

Y el afro sigue ahí. Enredado como siempre. Por tanto, me quedan por delante sesiones y sesiones con el peine.

Esos cuarenta minutos desenredando mi, hasta hace poco, odiado pelo (y ahora tan valorado) seguirán repitiéndose una y otra vez, permitiendo que otros microrrelatos autoetnográficos surjan y aumentando así mi historia de vida.

\section{Discurso teórico-conceptual}

Una vez analizados esos microrrelatos y compartiendo cómo me sentí en algunos momentos importantes de mi vida, vale la pena rescatar realidades escondidas tras ellos que, además de protagonizar estas narrativas personales, son comunes en nuestra sociedad actual y globalizada.

\section{Origen, Raíces, Identidad, Alteridad, Colectividad}

"Identidad es aproximadamente realidad preexistente" (Bauman, 2005, p. 39).

Partamos de las afirmaciones de Bauman (2005) en cuanto a que la gente no se plantearía tener una identidad si la pertenencia siguiera siendo su destino y una condición sin alternativa o al vincularla con un deseo de seguridad.

La propia definición que aporta la RAE define este concepto, que se vincula con lo individual y único, como el "conjunto de rasgos propios de un individuo o de una colectividad que los caracterizan frente a los demás" o la "conciencia que una persona tiene de ser ella misma y distinta a las demás".

De este modo, merece la pena analizar a Levinas y su definición de alteridad. Alter es un pronombre latino formado a partir del sustantivo alius -otro, distinto, diferente-, al que se añade el sufijo -ter, que diferencia a un elemento de otro dentro de un par. Así, alter se contrapone a ego, lo otro a lo mismo, pero ambas categorías se definen de modo relacional, remiten la una a la otra hasta el punto de que la identidad individual no se concibe sin incluir en esa definición la dimensión de alteridad, otredad o diferencia, con la que cada individualidad se relaciona. Para el filósofo lituano, la identidad individual se articula a partir de la relación con la alteridad; "es el Otro que viene hacia mí e interactúa conmigo lo que hace emerger mi identidad individual, y no al revés" (Fernández Guerrero, 2015, p. 423-424).

La razón del presente trabajo, al igual que afirma Kniffki (2014), no es homogeneizar, normalizar y armonizar, sino fomentar la diferencia y la ambivalencia en el marco de una actuación social colectiva.

Por tanto, esta investigación, que parte de mis propias emociones, procura vincular ese sentimiento individual con una realidad colectiva mayor; y es que, tal y como afirma Bolívar (2014, pp. 712-713) "si bien los relatos de vida siempre hacen referencia a la singularidad de una vida, refleja a la colectividad social de que se trate".

"Es posible leer una sociedad a través de una biografía" (Ferrarotti, 1983, p. 54).

\section{Memoria, Historia, Identidad}

La memoria no funciona de acuerdo con un orden temporal lineal; tampoco es un acto racional deliberado, sino que estalla a partir de asociaciones en un proceso siempre renovado de resignificación (Waldman, 2014).

"Recordar, como una actividad vital humana, define nuestros vínculos con el pasado; y las vías por las que recordamos, nos define en el presente" (Guasch, 2005, p. 158).

Candau (1998) afirma, muy en relación con el tema de la presente investigación, que la relación entre identidad y memoria deja claro que la identidad se manifiesta como un relato, un discurso autoreferenciado que se proyecta como una totalidad significante cimentada sobre tres bases: la naturaleza del acontecimiento recordado, el contexto simultáneo del suceso y el contexto del recuerdo (Silva, 2010).

Siguiendo las afirmaciones de Candau (1998), no puede haber identidad sin memoria porque sólo ésta permite la auto-conciencia de la duración. Tampoco 
puede haber memoria sin identidad, ya que el establecimiento de relaciones entre estados sucesivos del sujeto es imposible si este no tiene a priori un conocimiento de que esta cadena de secuencias temporales puede tener significado para él.

Si bien la memoria es un proceso individual, en el que se entreteje recuerdo y olvido configurando identidad, ella se encuentra inserta en redes de relaciones sociales sujetas a modificaciones en el tiempo y, por tanto, historizables. En este sentido, la memoria es también una construcción sociocultural a través de la cual se le da un significado a las experiencias pasadas de una comunidad; por ello, no puede ser monolítica u homogénea, sino plural, diversa, simultánea y en ocasiones contradictoria (Waldman, 2014).

"La memoria nos labra y nosotros, por nuestra parte, la modelamos a ella. Eso resume perfectamente la dialéctica de la memoria y la identidad, que se abrazan una a otra, se fecundan mutuamente, se funden y se refunden para producir una trayectoria de vida, una historia, un mito, un relato. Al final, por supuesto, sólo queda el olvido" (Candau, 1998, p. 13).

Migración, Multiculturalismo, Interculturalidad, Transculturalidad, Aculturación, Transculturación, Hibridación

Castles y Miller (2004, p. 33) definen de forma muy clara el término migración cuando lo presentan como "una acción colectiva que se origina en el cambio social y que afecta a toda la sociedad, tanto en las áreas de salida como en las de llegada". No hay parte ajena a la realidad social, por lo que es cosa de todos conocerla, comprenderla, ayudar en la medida que se pueda y quiera $\mathrm{y}$, sobre todo, respetar. Las relaciones que se puedan producir a raíz de las migraciones, del encuentro de culturas, es otro de los ejes del trabajo.

La multiculturalidad -interculturalidad cuando se convierte en dinámica- enriquece las relaciones y la democracia, ya que su perspectiva dinámica e interactiva se desarrolla en el ámbito de la mutua influencia, del sincretismo cultural, del deseo de un desarrollo global, enmarcado en los contextos de una sociedad cognitiva y global, y amparado por la revolución tecnológica. Según la UNESCO, cada cultura se nutre de sus propias raíces, pero sólo se desarrolla en contacto con las demás culturas (Martínez-Salanova, 2006).

Es interesante contemplar otros términos que han ido surgiendo para denominar la relación entre dos culturas. Por aculturación se entiende el proceso de tránsito de una cultura a otra y sus repercusiones sociales de todo género. Sin embargo, el vocablo transculturación expresa mejor las diferentes fases del proceso transitivo de una cultura a otra, porque éste no consiste solamente en adquirir una distinta cultura, sino que el proceso implica también necesariamente la pérdida o desarraigo de una cultura precedente, lo que pudiera decirse una parcial desculturación, y, además, significa la consiguiente creación de nuevos fenómenos culturales que pudieran denominarse de neoculturación (Chiappe, 2015; citando a Ortiz, 1983).

Aculturar significa tender a mejorar para crear otra cultura; recibir y asimilar la ayuda o los bienes aportados sin cuestionamientos. Mientras que transculturar, no sólo es adueñarse de estos beneficios, sino desterrar algunos rasgos, lo que implica desculturizar y ganar para legitimar otros valores (Villalobos y Ortega, 2012).

Un posible último punto para caracterizar el encuentro de culturas sería hibridación, la cual designa Néstor García Canclini como "la combinación de estructuras y procesos que en la cultura existían de forma separada, y que juntos forman nuevas organizaciones, la mayor de las veces con prácticas y sentidos novedosos" (Villalobos y Ortega, 2012, p. 34).

\section{Reflexiones}

"Sólo podemos vivir con nuestras diferencias si nos reconocemos mutuamente como sujetos diferentes" (Touraine, 1997, p. 5).

Empezaremos el final de la presente investigación totalmente de acuerdo con Bolívar (2014) cuando afirma que todo relato de vida es, en el fondo, una búsqueda de sentido y una justificación razonable que confirme o cuestione la trayectoria de vida seguida.

Existen beneficios realmente importantes en mi persona y en la forma de investigación en sí. Un autoconocimiento tremendo en mi caso, como artista, investigadora, docente $\mathrm{y}$, sobre todo, identidad individual. El hecho de que la investigación haya partido de mí ha fortalecido la vinculación con el tema a trabajar.

Vale la pena recalcar lo que señala Elías (1990) sobre la relación del "yo" con el "otro"; instancias recíprocas de autoconocimiento y construcción mutuas: el ser humano necesita a los otros para pertenecer y arraigarse a una identidad personal y colectiva.

Como se reflejaba al analizar la transculturación, la alteridad es el sustento del que el otro depende, de que sea aceptado y promovido, siempre y cuando esté controlado. En la transculturación el principio de alteridad consiste en el reconocimiento de la diferencia entre el yo, el otro y nosotros (Villalobos y Ortega, 2012).

Esta ha sido la respuesta a la pregunta con la que se empezaba el trabajo, ¿quién soy yo? Una respuesta válida a día de hoy, pero perfectamente flexible. Tal y como afirma Bolívar (2014), las historias de vida hacen visibles (para sí mismo y para otros) aquel conjunto de percepciones, intereses, dudas, orientaciones, hitos y circunstancias que han influido y configurado, de modo significativo, quien se es y por qué se actúa como se hace. La característica propia de la (auto)biografía es ser una construcción y configuración de la propia identidad, más que un relato fiel de la propia vida, que siempre está en proyecto de llegar a ser. Esta autointerpretación de la propia vida permite hacerla inteligible o darle significado.

Esos cuarenta minutos desenredando mi, hasta hace poco, odiado pelo (y ahora tan valorado) seguirán repitiéndose una y otra vez, permitiendo que otros microrrelatos autoetnográficos surjan y aumentando así mi historia de vida.

Cuando se narra una vida, no sólo se recoge lo que se ha aprendido en ella, sino que en el acto de narración en sí mismo sucede un aprendizaje en el que la reflexión 
juega un papel relevante. Tal y como señala Bolívar (2014, p. 720) citando a Alheit y Dausien (2008), el aprendizaje autobiográfico es una capacidad del sujeto para organizar de manera reflexiva sus experiencias y, haciendo esto, darse a sí mismo una coherencia personal y una identidad para atribuir un sentido a la historia de su vida para desarrollar sus capacidades de comunicación y de relación con el contexto social.

\section{Referencias}

Abad-Molina, J. Mesias-Lema, J.Mª y Martínez-Vérez, M.V. (2015): Arquitecturas del pensamiento: el lugar de las palabras.

Abad-Molina, J. Mesias-Lema, J.Mª y Martínez-Vérez, M.V. (2015): "La palabra como tipificación para decir la vida y decir al otro". En Arquitecturas del pensamiento: el lugar de las palabras. pp. 5-6.

Bauman, Z (2009). El arte de la vida. De la vida como obra de arte. Barcelona: Paidós. https://books.google.es/books?id=DhGdf2lL01gC\&pr intsec $=$ frontcover $\&$ hl=es\&source=gbs_ge_summary_ $\mathrm{r} \& \mathrm{cad}=0 \# \mathrm{v}=$ onepage $\& \mathrm{q} \& \mathrm{f}=$ false

Bruner, J. (1991). La autobiografía del yo. En Actos del significado. (pp. 101-133). Madrid: Alianza.

Bolívar, A (2014). "Las historias de vida del profesorado. Voces y contextos". Revista Mexicana de Investigación Educativa 19(62), 711-734. http://www.ugr.es/ abolivar/Publicaciones_files/Reci ente3_1.pdf

Candau, J. (2008). Memoria e Identidad. Buenos Aires: Ediciones del Sol.

Castles, S. e Miller, M. J. (2004). La era de la migración. México: Miguel Ángel Porrea librero-editor. (The Age of Migration, 1993). http://www.estudiosdeldesarrollo.mx/pagina_tipo_cua tro.php?libro=la_era_de_la_migracion

Fernández, O. (2015). "Levinas y la alteridad: cinco planos". Brocar 39 (1), 423-443. https://dialnet.unirioja.es/descarga/articulo/5257681.p df

Guasch, A.M. (2005). "Los lugares de la memoria: el arte de archivar y recordar". Materia 5, 157-183. www.raco.cat/index.php/Materia/article/viewFile/832 $33 / 112454$

Kniffki, J. (2014). "Las repercusiones de los procesos transnacionales en la vida cotidiana. Propuestas teóricas y metodológicas". En Espacios Transnacionales $\quad 2, \quad 52-60$. http://espaciostransnacionales.org/wp-content/uploads /2014/11/4-Repercusiones-procesos.pdf

Martínez-Salanova, E. (2006). "De la transculturación a la interculturalidad. Cómo presentan los medios la emigración, el mestizaje y las relaciones interétnicas". En Portularia 5, 45-53. Huelva: Universidad de Huelva.

https://dialnet.unirioja.es/servlet/articulo?codigo=213 4231\&info=resumen

Touraine, A. (1997). ¿Podremos vivir juntos? Iguales y diferentes. Madrid: PPC Editorial.

Villalobos, A. y Ortega, C. (2012). "Formas De interculturalidad en el arte: hibridación y transculturación”. En Ra-Ximhai 8 (3), 33-47. https://dialnet.unirioja.es/descarga/articulo/4730966.p df

Waldman, G. (2014). "La historia en primera persona: mirada(s) al pasado". En Política y Cultura 41, 91-109. http://www.redalyc.org/articulo.oa?id=26730752005 